\title{
Comparison of in vitro anti-lipase and antioxidant activities, and composition of commercial chokeberry juices
}

\author{
Dorota Sosnowska $^{1} \cdot$ Anna Podsędek $^{1} \cdot$ Alicja Z Kucharska $^{2} \cdot$ Małgorzata Redzynia $^{1} \cdot$ \\ Marzena Opęchowska ${ }^{1} \cdot$ Maria Koziołkiewicz ${ }^{1}$
}

Received: 9 July 2015 / Revised: 19 September 2015 / Accepted: 23 September 2015 / Published online: 8 October 2015

(C) The Author(s) 2015. This article is published with open access at Springerlink.com

\begin{abstract}
Inhibition of digestive lipases refers to the suppression of dietary fat absorption and, to some extent, to a strategy against overweight and obesity. In this study, the effect of five commercial black chokeberry juices on pancreatic lipase as a key enzyme relevant to obesity was investigated using as substrates triolein, sunflower oil, and rapeseed oil emulsions as well as 4-methylumbelliferyl oleate. The juices were also analyzed for antioxidant capacity $\left(\mathrm{ABTS}^{+}\right.$, DPPH, FRAP methods), qualitative and quantitative composition of phenolic compounds and nutrients. Significant differences were observed among their chemical compositions and biological activities. Chokeberry juices were rich in proanthocyanidins, followed by the hydroxycinnamic acids, anthocyanins, and flavonols. Their inhibitory activity against pancreatic lipase was related to polyphenol content, that of proanthocyanidins. The results reported herein have shown the influence of proanthocyanidin degree of polymerization on the inhibitory activity, especially in lipid emulsions. In conclusion, this work suggests that chokeberry juice may be a potential source of dietary fat absorption inhibitors, especially if it contains high molecular phenolic compounds.
\end{abstract}

Keywords Chokeberry juice - Anti-lipase activity · Antioxidant capacity $\cdot$ Phenolic profile

Anna Podsędek

anna.podsedek@p.lodz.pl

1 Institute of Technical Biochemistry, Faculty of Biotechnology and Food Sciences, Lodz University of Technology, Stefanowskiego 4/10, 90-924 Łódź, Poland

2 Department of Fruit, Vegetable and Cereals Technology, Wroclaw University of Environmental and Life Sciences, Chełmońskiego 37/41, 51-300 Wrocław, Poland

\section{Introduction}

Black chokeberry (Aronia melanocarpa) fruit is known as a potent source of phenolic compounds, especially anthocyanins and proanthocyanidins [1-4]. Nevertheless, chokeberry berries are rarely consumed directly because of their specific organoleptic properties, such as unpleasant astringent taste and their smell of bitter almonds [5]. So, it is preferable to use them for syrup, juice, jam, liqueur, and wine production. Moreover, processed berries have better flavor and are less bitter than the fresh fruits. One of the valuable products is chokeberry juice because one liter of the juice can contain up to $9 \mathrm{~g}$ of polyphenols, and chokeberry juice is one of the richest sources of these natural antioxidants among fruit juices [6].

An interest in chokeberry juices production has increased considerably in recent years, with a growing number of reports on their potential health benefits. Results of in vitro and in vivo studies indicate that chokeberry juice has cardioprotective [7, 8], hepatoprotective [9], and anti-diabetic effects [1] as well as anticancer activity [10]. Recent human studies also showed that Aronia melanocarpa juice may be useful in the treatment of obesity disorders [11]. Black chokeberry constituents may help in reducing dietary fat absorption by inhibiting digestive lipases activity. Pancreatic lipase inhibitory activity of black chokeberry extracts has been shown in in vitro studies using simple, different $p$-nitrophenyl esters or 4-methylumbelliferyl oleate as substrates [12,13]. The cited studies have shown anti-lipase activity dependence on the method of lipase activity determination [12] and on type of extraction agent [13].

Despite the data on anti-lipase activity of black chokeberry fruit extracts, there are no studies concerning 
chokeberry juices. The need for such data still exists due to insufficient intake of unprocessed berries, changes of bioactive compounds during chokeberry juice production, and increasing interest in healthy food consumption. Therefore, the objective of this study was to evaluate the inhibitory activities of five commercial $100 \%$ black chokeberry juices against porcine pancreatic lipase using different in vitro assays. The pancreatic lipase is one of the most widely studied targets for phytochemicals acting as antiobesity agents because it is responsible for the hydrolysis of $50-70 \%$ of total dietary fats in the intestinal lumen [14]. Because in gastrointestinal tract the substrates for the water-soluble pancreatic lipase are usually lipid droplets embedded in an aqueous medium [15], we decided to use systems with triolein (glycerol trioleate), rapeseed oil, and sunflower oil emulsions in order to better simulate physiological conditions. Porcine pancreatic lipase activity was also determined by the method using 4-methylumbelliferyl oleate (4-MUO) as substrate because of its wide application. Basic chemical composition and qualitative and quantitative phenolic compounds composition as well as antioxidant capacity of juices were also evaluated.

\section{Materials and methods}

\section{Materials and reagents}

Chokeberry juices (100\% of fruit) of five different brands in glass bottles, rapeseed oil (Kruszwica S.A., Poland), and sunflower oil (PPHU Olmaj, Poland) were purchased from local markets (Łódź, Poland). Juice samples for analysis were obtained after mixing the contents of three bottles. Lipase (EC 3.1.1.3) from porcine pancreas type II, Trisbase, triolein (glycerol trioleate), bile acids from bovine and ovine, 4-methylumbelliferyl oleate (4-MUO), organic acids and sugars standards, sorbitol, quercetin, (+)-catechin, (-)-epicatechin, gallic acid, naringenin, ascorbic acid, 2,2'-azino-bis(3-ethylbenzothiazoline-6-sulfonic acid) (ABTS), 2,2-diphenyl-1-picrylhydrazyl (DPPH), 2,4,6-tris-2-pyridyl-s-triazine (TPTZ), 6-hydroxy-2,5,7,8tetramethylchroman-2-carboxylic acid (Trolox), phloroglucinol, potassium persulfate, dimethyl sulfoxide (DMSO), formic acid, methanol, and acetonitrile were obtained from Sigma-Aldrich (Steinheim, Germany). Cyanidin 3-glucoside, cyanidin 3-galactoside, 5- $O$-caffeoylquinic acid, $p$-coumaric acid, protocatechuic acid, quercetin 3-O-glucoside, quercetin 3-O-galactoside, quercetin 3-O-rutinoside, quercetin, isorhamnetin 3-O-galactoside were obtained from Extrasynthese (Lyon, France). Procyanidins B2 and B3, 3-caffeoylquinic acid, and 4-caffeoylquinic acid were purchased from TransMIT (Gießen, Germany), and procyanidin B1 from PhytoLab (Vestenbergsgreuth, Germany).
Acetic acid was obtained from J.T. Baker (Łódź, Poland). Sodium hydroxide and sodium carbonate were purchased from Chempur (Piekary Śląskie, Poland). Other reagents were obtained from POCH (Gliwice, Poland). Ultrapure water (Simplicity ${ }^{\mathrm{TM}}$ Water Purification System, Millipore, Marlborough, MA, USA) was used to prepare all solutions.

\section{Quality parameters}

Total soluble solids, $\mathrm{pH}$, organic acids, and sugars contents were evaluated as quality indexes. The $\mathrm{pH}$ values were measured using a $\mathrm{pH}$-meter (CyberScan $\mathrm{pH}$ 510, Eutech Instruments, Singapore). The total soluble solids were recorded in a refractometer Abbe 2 WAY (Vanco Industries, Ningbo, China) at $20{ }^{\circ} \mathrm{C}$, with values being expressed as ${ }^{\circ}$ Brix. Individual sugars (glucose, fructose, sucrose) and sorbitol were determined by HPLC method described by Sójka and Król [16] using Aminex HPX87C column $(300 \times 7.8 \mathrm{~mm})$ from BioRad (Hercules, California, USA) at $85{ }^{\circ} \mathrm{C}$ and the refractive index (RI) detector (Knauer K-2301) with a Knauer integrating system (Berlin, Germany). The mobile phase was water, and the flow rate was $0.5 \mathrm{ml} / \mathrm{min}$. The injection volume was $20 \mu \mathrm{l}$. The juice before injection was cleaned on SPE column containing cation exchanger resin Amberlite IR120 and anion exchanger resin Amberlite IRA420 at a volumetric ratio of $1: 2$. The results were expressed as gram of individual sugar per 11 of juice. Individual organic acids (citric, malic, oxalic, and tartaric) were analyzed by HPLC method using the HPLC Knauer system (Berlin, Germany) consisted of a UV-Vis detector set at $210 \mathrm{~nm}$ and a LiChrospher-100 RP-18 column $(250 \times 4.6 \mathrm{~mm} ; 5 \mu \mathrm{m})$ operated at $25{ }^{\circ} \mathrm{C}$. The isocratic mobile phase consisted of mixture of $0.5 \%$ water solution of diammonium hydrogen phosphate adjusted to $\mathrm{pH} 2.24$ with phosphoric acid and acetonitrile (99.98:0.02, v/v). Samples were eluted at a flow rate of $1 \mathrm{ml} / \mathrm{min}$. The injection volume was $20 \mu \mathrm{l}$. The juices were centrifuged at 13,000 rpm for $5 \mathrm{~min}$, and each supernatant was filtered through a $0.20-\mu \mathrm{m}$ Minisart RC4 filter (Sartorius, Stedim Biotech $\mathrm{GmbH}$, Germany) before injection into the HPLC system. The results were expressed as gram of individual organic acid per 11 of juice.

\section{Spectrophotometric determination of phenolic compounds}

Total phenolics content was determined using Folin-Ciocalteu reagent as we described in our previous work [12]. The absorbance of reaction mixture (juice, Folin-Ciocalteu reagent, sodium carbonate, and water) was read at $760 \mathrm{~nm}$ after 20 min incubation at ambient temperature. Total phenolics content was expressed as g of gallic acid equivalents (GAE) per 11 of juice. Total anthocyanins content 
was quantified by a pH-differential [6]. Juices were diluted (50-200 times) with two buffer solutions at $\mathrm{pH} 1$ and 4.5, and absorbance was measured at 515 and $700 \mathrm{~nm}$ after $1 \mathrm{~h}$ incubation at ambient temperature in the dark. The results were expressed as g of cyanidin 3-glucoside equivalents (CGE) per 11 of juice using a molar extinction of cyanidin 3-glucoside of 26,900 1/mol cm and molar weight of $449.2 \mathrm{~g} / \mathrm{mol}$. The content of total proanthocyanidins in juices was determined after acid depolymerization to the corresponding anthocyanidins as described by Rösch et al. [17]. In fact, $0.1 \mathrm{ml}$ of diluted (2-20 times) juice was mixed with $9.9 \mathrm{ml}$ of a solution of concentrated hydrochloric acid in $n$-butanol $(1: 9, \mathrm{v} / \mathrm{v})$ and heated for $90 \mathrm{~min}$ in a boiling water bath. After cooling in ice, the absorbance of sample was measured at $550 \mathrm{~nm}$. The content of proanthocyanidins was calculated by the molar extinction coefficient of cyani$\operatorname{din}(\varepsilon=17,360 \mathrm{l} / \mathrm{mol} \mathrm{cm}$ and molar mass $287 \mathrm{~g} / \mathrm{mol})$ and was expressed as gram of cyanidin equivalents (CYE) per 11 of juice.

\section{Identification of individual phenolic compounds by UPLC-MS}

Phenolic compounds were identified using the Acquity UPLC system coupled with a quadrupole-time-of-flight (Q-TOF) MS instrument (Waters Corp., Milford, MA, USA) with an electrospray ionization (ESI) source. Separation was achieved on an AcquityTM BEH C18 column $(100 \times 2.1 \mathrm{~mm}, 1.7 \mu \mathrm{m}$; Waters $)$. The mobile phase was a mixture of $0.1 \%$ formic acid (A) and acetonitrile (B). The gradient program was as follows: initial conditions-1\% $\mathrm{B}$ in $\mathrm{A}, 12 \mathrm{~min}-25 \% \mathrm{~B}$ in $\mathrm{A}, 12.5 \mathrm{~min}-100 \% \mathrm{~B}$, $13.5 \mathrm{~min}-1 \% \mathrm{~B}$ in $\mathrm{A}$. The flow rate was $0.42 \mathrm{ml} / \mathrm{min}$, and the injection volume was $5 \mu \mathrm{l}$. The column was operated at $30{ }^{\circ} \mathrm{C}$. The major operating parameters for the Q-TOF-MS were described in the previous work [18]. The juices were centrifuged at 13,000 rpm for $5 \mathrm{~min}$, and each supernatant was filtered through a $0.20-\mu \mathrm{m}$ Minisart RC4 filter (Sartorius, Stedim Biotech GmbH, Germany) before injection into the UPLC system. The data were collected by MassLynxTM V 4.1 software. Polyphenolic compounds were putatively identified using their UV-Vis characteristic, MS, and $\mathrm{MS}^{2}$ properties using data gathered in-house and from the literature.

\section{Quantitative determination of phenolics by HPLC}

Phenolic compounds were quantified using Dionex HPLC system (Germering, Germany) equipped with the Ultimate 3000 model diode array detector. The detector cooperated with the LPG-3400A pump, EWPS-3000SI autosampler, column thermostat TCC-3000SD, and Chromeleonv 6.8 software. Cadenza Imtakt column C5-C18 $(75 \times 4.6 \mathrm{~mm})$ with a guard column was used. The mobile phase was composed of solvent A ( $4.5 \%$ formic acid, v/v) and solvent B (acetonitrile). The elution system was as follows: $0-1 \mathrm{~min}$ $5 \% \mathrm{~B} ; 20 \min 25 \% \mathrm{~B} ; 21 \min 100 \% \mathrm{~B} ; 26 \min 100 \%$ B; 27 min $5 \%$ B. The flow rate of the mobile phase was $1.0 \mathrm{ml} / \mathrm{min}$, and the injection volume was $20 \mu \mathrm{l}$. The column was operated at $30{ }^{\circ} \mathrm{C}$. The runs were monitored at $245 \mathrm{~nm}$ (protocatechuic acid and depside), $280 \mathrm{~nm}$ (flavanone), $320 \mathrm{~nm}$ (phenolic acids), $360 \mathrm{~nm}$ (flavonols), and $520 \mathrm{~nm}$ (anthocyanins) wavelengths. Caffeoylquinic acid isomers were quantified as 5-O-caffeoylquinic acid, $p$-coumaric acid derivatives as $p$-coumaric acid, anthocyanins as cyanidin 3-O-glucoside, quercetin derivatives as quercetin 3-O-glucoside, izorhamnetin derivative as isorhamnetin 3-O-galactoside, and protocatechuic acid and depside 1 as protocatechuic acid, eriodictyol 7-glucuronide as naringenin. The results were calculated as $\mathrm{mg}$ of compound in 11 of juice.

\section{Determination of mean degree of polymerization of proanthocyanidins}

Acid-catalyzed degradation of polymeric proanthocyanidins in the excess of phloroglucinol was used to determine proanthocyanidins mean degree of polymerization (mDP). Direct phloroglucinolysis of freeze-dried chokeberry juices (40-60 mg) was performed as described Wojdyło et al. [19]. The products of acid degradation of proanthocyanidins were separated by the use of the HPLC system (Waters, Milford, MA) that consisted of a gradient pump (1525), fluorescence detector (2475), auto-injector (2707), and Breeze 2 system controller equipped with a $250 \times 4.6 \mathrm{~mm}$ id, $5 \mu \mathrm{m}$ Symmetry C18 column (Waters). The mobile phase was a binary gradient with A, water/acetic acid $(97.5: 2.5, \mathrm{v} / \mathrm{v})$, and $\mathrm{B}$, water/acetonitrile (20:80, $\mathrm{v} / \mathrm{v})$, with a flow rate of $1 \mathrm{ml} / \mathrm{min}$, and the gradient program used was according to Sójka et al. [20]. The injection volume was $20 \mu 1$. The fluorescence detection was recorded at an excitation wavelength of $278 \mathrm{~nm}$ and an emission wavelength of $360 \mathrm{~nm}$. The calibration curves, which were based on peak area, were established using (+)-catechin, (-)-epicatechin, procyanidins B1, B2, and B3 after hydrolysis reaction as (+)-catechin-phloroglucinol and (-)-epicatechin-phloroglucinol adducts standards. The mDP was calculated as the molar ratio of all the flavan-3-ol units (phloroglucinol adducts + terminal units) to (-)-epicatechin and $(+)$-catechin, which correspond to terminal units.

\section{Assays for pancreatic lipase activity}

The release of free fatty acids from three emulsified lipids (i.e., triolein, sunflower oil, and rapeseed oil) catalyzed by porcine pancreatic lipase was calculated on the basis of the volume of 
$\mathrm{NaOH}$ added as described in our previous work [21]. Titration was carried out using an automatic $\mathrm{pH}-$ stat titrator (SCHOTT Instruments $\mathrm{GmbH}$ ). All assays were carried out at $37^{\circ} \mathrm{C}$ and $\mathrm{pH}$ 7.4. The oil-in-water emulsions were prepared by mechanical stirring of lipid substrates with $20 \mathrm{mM}$ Tris-base buffer (pH 7.4) containing $150 \mathrm{mM} \mathrm{NaCl}$ and $1.3 \mathrm{mM} \mathrm{CaCl}_{2}$, and bile acids (triolein emulsion) or both bile acids and gum arabic (oil emulsions) in high-speed blender (PRO200, Bioeko) in an ice bath for $5 \mathrm{~min}$ at 20,000 rpm. Triolein emulsion contained $2.34 \mathrm{~g}$ of triolein, $1.56 \mathrm{~g}$ of bile acids, and $100 \mathrm{ml}$ of buffer, while oil emulsion included $4 \mathrm{~g}$ of oil, $1 \mathrm{~g}$ of bile acids and $1 \mathrm{~g}$ of gum arabic, and $100 \mathrm{ml}$ of buffer. Pancreatic lipase was dissolved in the same Tris-base buffer at $10 \mathrm{mg} / \mathrm{ml}$ and then centrifuged at 13,000 rpm for $5 \mathrm{~min}$. Directly before analysis, the juices were adjusted to $\mathrm{pH} 7.2-7.4$ with $6 \mathrm{M} \mathrm{NaOH}$ (the initial $\mathrm{pH}$ values were $3.42-3.72$ ). Briefly, $4 \mathrm{ml}$ of the emulsified substrate solution and $2 \mathrm{ml}$ of juice or buffer (control sample) were transferred into a clean $25-\mathrm{ml}$ glass bottle. The reaction mixtures were pre-incubated at $37{ }^{\circ} \mathrm{C}$ for $5 \mathrm{~min}$ before adding lipase supernatant $-0.5 \mathrm{ml}$ into triolein emulsion or $1 \mathrm{ml}$ into oil emulsion. For each sample, a separate blank without lipase was used for background subtraction. Finally, the reaction mixtures were incubated in a shaking bath $(200 \mathrm{rpm})$ at $37^{\circ} \mathrm{C}$ for $30 \mathrm{~min}$. The reaction was terminated by adding $14 \mathrm{ml}$ of ethanol, and the resultant mixture was automatically titrated to $\mathrm{pH} 8$ using a pH-stat with $10 \mathrm{mM} \mathrm{NaOH}$ solution. All samples were assayed in triplicate. The inhibition of lipase activity (percentage) was calculated using the following formula: of inhibition rate against the juice concentration. The lower $\mathrm{IC}_{50}$ indicates the higher anti-lipase activity.

\section{Analysis of antioxidant capacity}

Free radical scavenging activity of chokeberry juices using the free radical cation $\mathrm{ABTS}^{+}{ }^{+}$was performed as described by Re et al. [22]. The DPPH scavenging radical assay was conducted according to Kim et al. [23]. FRAP was performed according to Benzie and Strain [24]. For all methods, juices were diluted with water 30-400 times. The antioxidant capacity was evaluated by measuring the absorbance at $734 \mathrm{~nm}$ after 6 min of reaction with the radical $\left(\mathrm{ABTS}^{+}\right)$, at $517 \mathrm{~nm}$ after $30 \mathrm{~min}$ (DPPH), and at 593 after $10 \mathrm{~min}$ for FRAP. For all methods, standard curves were prepared using different concentrations of Trolox (water-soluble derivative of vitamin E). The results obtained were expressed as mmol Trolox equivalents (TE) per 11 of juice.

\section{Statistical analysis}

Data were expressed as mean $\pm \mathrm{SD}$. Data were analyzed by means of a one-way analysis of variance (ANOVA). A Duncan post hoc test was used to determine differences between the means with significance level $p<0.05$. Pearson's correlation coefficients $(r)$ were determined using Microsoft Excel XP in order to define the relationships between selected parameters.

Lipase inhibition $(\%)=\frac{\left(V_{\text {control }}-V_{\text {control blank }}\right)-\left(V_{\text {sample }}-V_{\text {sample blank }}\right)}{\left(V_{\text {control }}-V_{\text {control blank }}\right)} \times 100$

where $V$ is the volume $(\mathrm{ml})$ of $10 \mathrm{mM} \mathrm{NaOH}$ required to neutralize the free fatty acids produced.

Lipase activity was also measured using 4-MUO as substrate according to our previous work [12]. The amount of 4-methylumbelliferone released by lipase was measured with a microplate reader (Synergy ${ }^{\mathrm{TM}} 2$, BioTek Instruments Inc.) at an excitation wavelength of $360 \mathrm{~nm}$ and at an emission wavelength of $460 \mathrm{~nm}$. The inhibition (\%) was calculated by using the following formula:

\section{Results}

\section{Effect of chokeberry juices on pancreatic lipase activity}

The effect of five commercial black chokeberry juices on the porcine pancreatic lipase activity was assessed in vitro using a $\mathrm{pH}-$ stat method with three different lipid substrates: triolein (glycerol trioleate), sunflower oil, and rapeseed oil. Independently, lipase activity was determined by fluorimetric

Lipase inhibition $(\%)=\frac{\left(F_{\text {control }}-F_{\text {control blank }}\right)-\left(F_{\text {sample }}-F_{\text {sample blank }}\right)}{\left(F_{\text {control }}-F_{\text {control blank }}\right)} \times 100$

where $F_{\text {control }}$ and $F_{\text {control blank }}$ are fluorescence values of the solvent control with and without 4-MUO, respectively; $F_{\text {sample }}$ and $F_{\text {sample blank }}$ are fluorescence values of the juice with and without 4-MUO, respectively.

The concentration which inhibits pancreatic lipase activity by $50 \%\left(\mathrm{IC}_{50}\right)$ was determined on the basis of the graph method with 4-MUO as substrate. The results, expressed as $\mathrm{IC}_{50}$ values, are given in Table 1 . The $\mathrm{IC}_{50}$ values varied from 0.59 to $5.84 \mu \mathrm{l}$ of juice/ml of reaction mixture in the fluorimetric method and from 27.79 to $221.66 \mu 1$ of juice/ $\mathrm{ml}$ in the $\mathrm{pH}$-stat method. Two juices (brands 4 and 5) at the highest doses (307.7 $\mu \mathrm{l}$ of juice/ml of reaction mixture) in 
Table 1 Inhibition of pancreatic lipase as $\mathrm{IC}_{50}(\mu 1$ of juice/ml of reaction mixture) values of chokeberry juices determined using different substrates

\begin{tabular}{|c|c|c|c|c|c|}
\hline \multirow[t]{2}{*}{ Substrates } & \multicolumn{5}{|c|}{ Juices of different brands } \\
\hline & 1 & 2 & 3 & 4 & 5 \\
\hline 4-Methylumbelliferyl oleate & $0.59 \pm 0.01$ & $1.42 \pm 0.02$ & $1.45 \pm 0.06$ & $3.30 \pm 0.04$ & $5.84 \pm 0.06$ \\
\hline Triolein & $27.79 \pm 0.63$ & $86.93 \pm 1.58$ & $221.66 \pm 0.31$ & - & - \\
\hline Sunflower oil & $53.12 \pm 0.39$ & $172.63 \pm 1.80$ & - & - & - \\
\hline Rapeseed oil & $55.34 \pm 0.78$ & $188.11 \pm 2.05$ & - & - & - \\
\hline
\end{tabular}

Values are mean $\pm \mathrm{SD}, n=3$. Samples without data did not inhibit $50 \%$ of enzyme

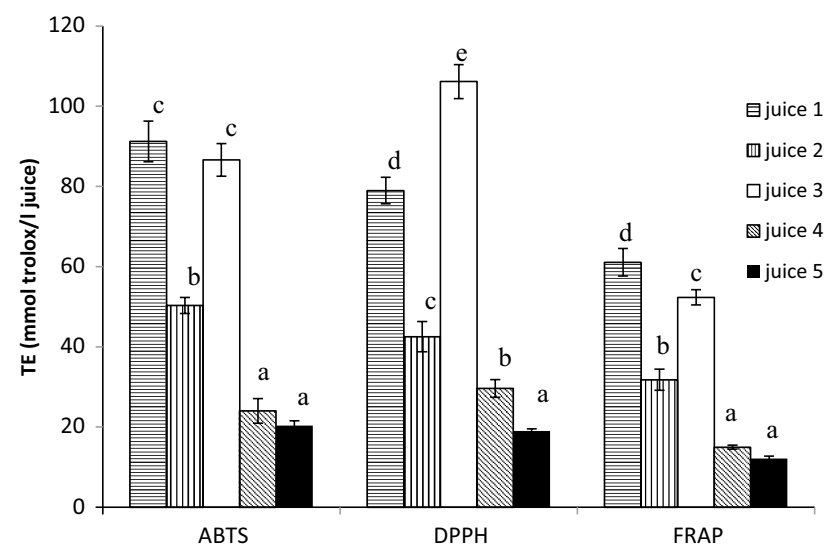

Fig. 1 Antioxidant capacity of chokeberry juices determined by different methods. Different letters denote significant differences $(p<0.05)$ between juices, $n=5$

the conditions of the assay did not inhibit pancreatic lipase in triolein emulsion. In the case of both oil emulsion systems, three juices at the highest concentration $(285.7 \mu l$ of juice/ml of reaction mixture) did not affect enzyme activity.

\section{Antioxidant capacity of chokeberry juices}

In the present work, three methods (ABTS, DPPH, and FRAP) were selected for the evaluation of the antioxidant capacity of the chokeberry juices tested because the determination of antioxidant capacity of complex food matrix is still an unresolved problem. The Trolox equivalents (TE) values were calculated in order to compare the chokeberry juices, as shown in Fig. 1. Significant differences $(p<0.05)$ in the antioxidant capacity were found for the analyzed juices. The
TE values varied in the ranges $20.39-91.21 \mathrm{mmol} / \mathrm{l}$ of juice, 19.02-106.13 $\mathrm{mmol} / \mathrm{l}$, and 12.19-61.09 $\mathrm{mmol} / \mathrm{l}$ as determined by ABTS, DPPH, and FRAP method, respectively. The ranking order of the antioxidant capacities was the same for ABTS and FRAP methods, while juice of brand 3 was more active than juice brand 1 in DPPH method.

\section{Phenolic compounds of chokeberry juices}

The black chokeberry juices were analyzed for the content of total phenolics, total anthocyanins, and total proanthocyanidins using a Folin-Ciocalteu, a pH-differential, and acid depolymerization methods, respectively. As it is shown in Table 2, significant differences have been observed for the commercial juices tested $(p<0.05)$, which were about fourfold for total phenolics (2.73-10.35 g GAE/l) and about sevenfold in the case of total anthocyanins $(0.10$ $0.67 \mathrm{~g} \mathrm{CGE} / \mathrm{l})$ and total proanthocyanidins (0.64-4.17 g CYE/1). Proanthocyanidins accounted for 29.8-40.3\%, while anthocyanins contributed only for 3.6-6.7 \% of total phenolic content. The mean size of proanthocyanidin molecules described by their $\mathrm{mDP}$ was very diverse for the juices tested and ranged from 12 to 52 .

Additionally, the juices with the highest anti-lipase and antioxidant activities (three brands) were analyzed for the phenolic profiles by UPLC-MS and for the content of individual phenolic compounds using HPLC system. Representative HPLC chromatograms of chokeberry juice are presented in Fig. 2. The results of qualitative and quantitative phenolic composition in black chokeberry juices are summarized in Table 3 . The results showed that chlorogenic acids dominated in the group of low molecular

Table 2 Content of total phenolics, anthocyanins, and proanthocyanidins ( $\mathrm{g} / \mathrm{l}$ of juice), and $\mathrm{mDP}$ of the proanthocyanidins of chokeberry juices

\begin{tabular}{lccccc}
\hline Phenolic compounds & \multicolumn{4}{l}{ Juices of different brands } & \\
\cline { 2 - 6 } & 1 & 2 & 3 & 4 & 5 \\
\hline Total phenolics $(n=4)$ & $10.35 \pm 0.33 \mathrm{e}$ & $6.09 \pm 0.09 \mathrm{c}$ & $10.01 \pm 0.35 \mathrm{~d}$ & $3.49 \pm 0.06 \mathrm{~b}$ & $2.73 \pm 0.07 \mathrm{a}$ \\
Total anthocyanins $(n=3)$ & $0.57 \pm 0.04 \mathrm{~d}$ & $0.29 \pm 0.02 \mathrm{~d}$ & $0.67 \pm 0.02 \mathrm{e}$ & $0.14 \pm 0.07 \mathrm{~b}$ & $0.10 \pm 0.01 \mathrm{a}$ \\
Total proanthocyanidins $(n=3)$ & $4.17 \pm 0.61 \mathrm{e}$ & $2.10 \pm 0.07 \mathrm{c}$ & $3.82 \pm 0.08 \mathrm{~d}$ & $1.04 \pm 0.01 \mathrm{~b}$ & $0.64 \pm 0.01 \mathrm{a}$ \\
$\mathrm{mDP}(n=2)$ & $52 \pm 3 \mathrm{~d}$ & $43 \pm 1 \mathrm{c}$ & $23 \pm 3 \mathrm{~b}$ & $25 \pm 2 \mathrm{~b}$ & $12 \pm 3 \mathrm{a}$ \\
\hline
\end{tabular}

Values are mean $\pm \mathrm{SD}$. Values that are followed by different letters within each row are significantly different $(p<0.05)$; $n$ number of measurements; $m D P$ mean degree of polymerization of the proanthocyanidins 
Fig. 2 Representative highperformance liquid chromatography (HPLC) chromatograms of chokeberry juice recorded at 280, 320, and $520 \mathrm{~nm}$. Peak identification and their MS data are shown in Table 3; ni-not identified
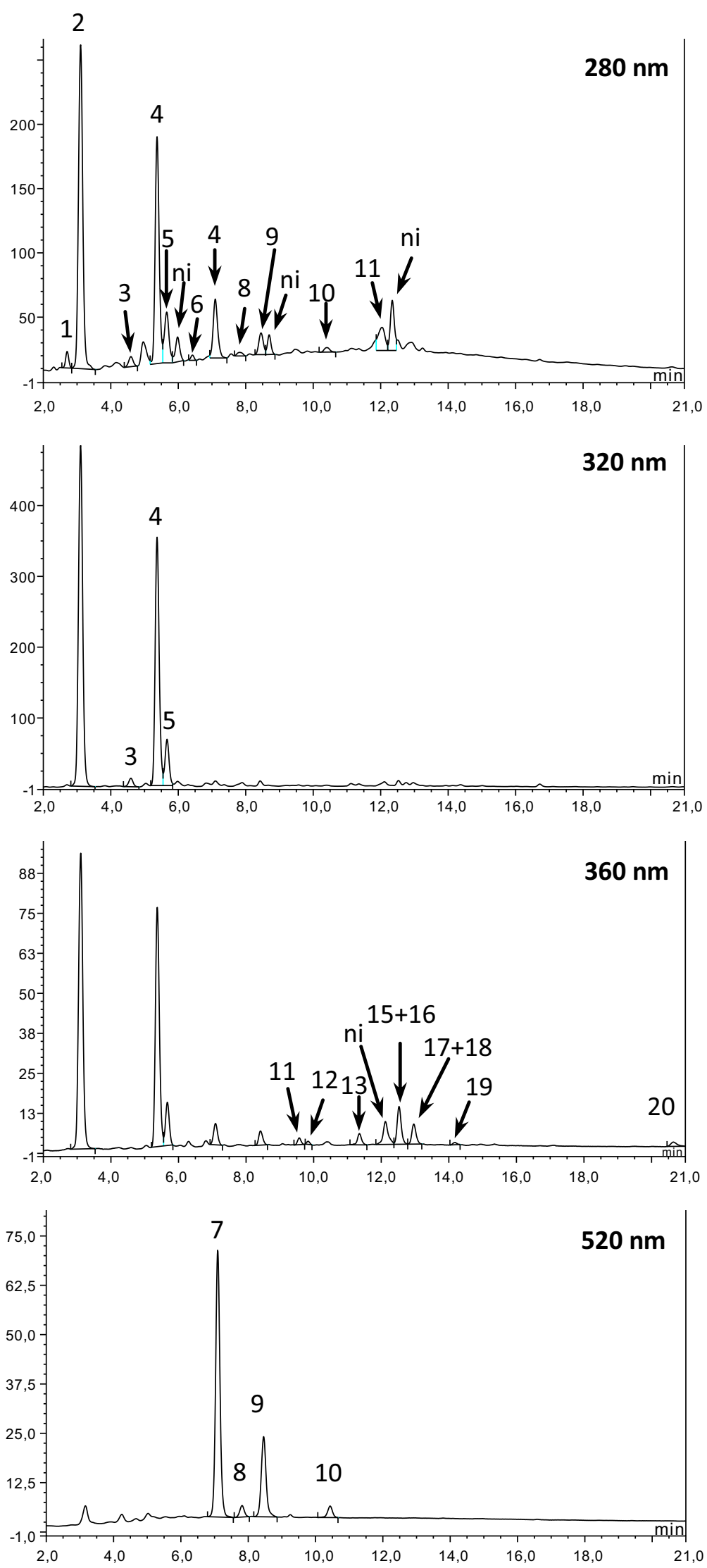
Table 3 Chromatographic profile and quantification of phenolic compounds identified in chokeberry juices

\begin{tabular}{|c|c|c|c|c|c|c|c|}
\hline \multirow[t]{2}{*}{ Peak } & \multirow[t]{2}{*}{$\mathrm{UV}-\mathrm{Vis}(\mathrm{nm})$} & \multirow[t]{2}{*}[\mathrm{M}-\mathrm{H}]{$^{-1} /[\mathrm{M}+\mathrm{H}]^{+1}(m / z)$} & \multirow[t]{2}{*}{ Fragments $(m / z)$} & \multirow[t]{2}{*}{ Identity } & \multicolumn{3}{|c|}{ Content (mg/l) } \\
\hline & & & & & Juice 1 & Juice 2 & Juice 3 \\
\hline 1 & 261,294 & 153.0204 & 109 & Protocatechuic acid & 24.93 & 27.04 & 57.35 \\
\hline 2 & 245,325 & 353.0879 & $191 / 179$ & 3-O-caffeoylquinic acid & 642.28 & 463.31 & 466.35 \\
\hline 3 & 311 & 337.0937 & $191 / 163$ & $p$-Coumaroylquinic acid ${ }^{\mathrm{a}}$ & 3.66 & 2.72 & 3.51 \\
\hline 4 & 245,325 & 353.0879 & $191 / 179$ & 5-O-caffeoylquinic acid & 442.33 & 323.67 & 426.23 \\
\hline 5 & 245,325 & 353.0879 & $191 / 179$ & 4-O-caffeoylquinic acid & 80.65 & 34.56 & 86.51 \\
\hline 6 & 266,299 & 319.0454 & $301 / 165$ & Depside $^{a}$ & 3.66 & 2.15 & 6.30 \\
\hline 7 & 515 & 447.0916 & 285 & Cyanidin 3-O-galactoside & 96.88 & 46.58 & 48.01 \\
\hline 8 & 515 & 447.0916 & 285 & Cyanidin 3-O-glucoside & 4.37 & 2.01 & 2.44 \\
\hline 9 & 516 & 417.0813 & 285 & Cyanidin 3-O-arabinoside ${ }^{\mathrm{a}}$ & 32.59 & 14.76 & 11.47 \\
\hline 10 & 516 & 417.0813 & 285 & Cyanidin 3-O-xyloside ${ }^{\mathrm{a}}$ & 4.74 & 1.64 & 1.24 \\
\hline 11 & 258,353 & 625.1437 & 301 & Quercetin 3-O-dihexoside ${ }^{a}$ & 4.32 & 3.61 & 19.56 \\
\hline 12 & 257,353 & 625.1437 & 301 & Quercetin 3-O-dihexoside ${ }^{\mathrm{a}}$ & 1.71 & 1.39 & 9.83 \\
\hline 13 & 257,355 & 595.1312 & 301 & Quercetin 3-O-vicianoside ${ }^{\mathrm{a}}$ & 8.80 & 9.10 & 43.48 \\
\hline 14 & 284 & 463.0887 & 287 & Eriodictyol 7-glucuronide $^{\mathrm{a}}$ & 48.60 & 24.31 & 64.88 \\
\hline 15 & 257,355 & 609.1483 & 301 & Quercetin 3-O-robinobioside ${ }^{\mathrm{a}}$ & 28.63 & 23.59 & 118.89 \\
\hline 16 & 257,354 & 463.0887 & 301 & Quercetin 3-O-galactoside & & & \\
\hline 17 & 257,354 & 609.1483 & 301 & Quercetin 3-O-rutinoside & 15.70 & 13.33 & 53.42 \\
\hline 18 & 257,354 & 463.0887 & 301 & Quercetin 3-O-glucoside & & & \\
\hline 19 & 255,355 & 623.1598 & 315 & Isorhamnetin 3-O-rhamnosylhexoside ${ }^{\mathrm{a}}$ & 1.13 & 0.81 & 4.80 \\
\hline \multirow[t]{2}{*}{20} & 255,373 & 301.0354 & 151 & Quercetin & 5.02 & 1.75 & 22.73 \\
\hline & & & & Total & 1450.00 & 996.33 & 1447.00 \\
\hline
\end{tabular}

Values are the means $(n=2)$

a Tentatively identified

phenolic compounds and they represented $67.7-82.4 \%$ of phenolics. Flavonols in chokeberry juices were mainly a mixture of quercetin glycosides and constituted only 4.5$18.8 \%$ of phenolics. The contribution of anthocyanins in total phenolics varied from $4.4 \%$ in juice brand 3 to $9.6 \%$ in juice brand 1 . Cyanidin 3-O-galactoside and cyanidin 3-O-arabinoside were the main anthocyanins in the tested chokeberry juices.

\section{Basic parameters of the juices studied}

The basic chemical composition of five commercial chokeberry juices is given in Table 4 . Statistically significant differences $(p<0.05)$ in all quality parameters tested were found in chokeberry juices produced by different companies. The minimum and maximum $\mathrm{pH}$ values were measured as 3.42 and 3.72 , and the total soluble solids ( ${ }^{\circ}$ Brix) values ranged from 12.5 to 20.1. Total content of fructose, glucose, sucrose, and sorbitol varied significantly from 89.5 to $162.4 \mathrm{~g} / \mathrm{l}$ of juice. Sorbitol dominated in all juices and amounted to $39.5-47.6 \%$ of total sugars. Sucrose was noted only in two juices at 1.7 and $3.0 \mathrm{~g} / \mathrm{l}$. The total organic acids content in the juices tested varied from $12.3 \mathrm{~g} / \mathrm{l}$ to $21.9 \mathrm{~g} / \mathrm{l}$ with significant differences dependently on the brands $(p<0.05)$. The amounts of organic acids analyzed were ordered as malic acid $>$ tartaric acid $>$ citric acid $>$ oxalic acid. Malic acid amounted to $52.6-60.9 \%$ of total organic acids content.

\section{Discussion}

Obesity is one of the most rapidly expanding metabolic disorders, and therefore, its prophylaxis is a big challenge for the world. Reduced absorption of dietary fat from the intestine by the inhibition of digestive lipases, especially pancreatic lipase, is an approach to decreasing the risk of obesity [15]. The presence of pancreatic lipase inhibitors has recently been reported in some edible fruits, including black chokeberry [12, 13, 21, 25-29]. Inhibition of this enzyme by fruits is attributed to the phenolic compounds, such as proanthocyanidins [12, 21, 27], ellagitannins [25, 26], anthocyanins [13, 28], and flavones [29]. The present study reports that proanthocyanidins accounted for 29.8-40.3\%, while anthocyanins contributed only for $3.6-6.7 \%$ of total phenolic content $(2.73-10.35 \mathrm{~g} / \mathrm{l})$ in the 
Table 4 Total soluble solids, $\mathrm{pH}$ values, and profiles of organic acids and sugars of chokeberry $100 \%$ juices

\begin{tabular}{|c|c|c|c|c|c|}
\hline \multirow[t]{2}{*}{ Component } & \multicolumn{5}{|c|}{ Juices of different brands } \\
\hline & 1 & 2 & 3 & 4 & 5 \\
\hline $\mathrm{pH}(n=2)$ & $3.72 \pm 0.01 \mathrm{c}$ & $3.69 \pm 0.02 \mathrm{c}$ & $3.42 \pm 0.03 a$ & $3.60 \pm 0.04 b$ & $3.48 \pm 0.04 \mathrm{a}$ \\
\hline Soluble solids $\left({ }^{\circ}\right.$ Brix $)(n=2)$ & $20.10 \pm 0.28 \mathrm{c}$ & $16.00 \pm 0.14 b$ & $12.50 \pm 0.57 \mathrm{a}$ & $14.50 \pm 0.28 b$ & $12.60 \pm 0.21 \mathrm{a}$ \\
\hline \multicolumn{6}{|c|}{ Sugars/sugar alcohol $(g / l)(n=2)$} \\
\hline Fructose & $40.56 \pm 0.25 c$ & $41.18 \pm 0.19 c$ & $27.44 \pm 0.53 a$ & $33.26 \pm 1.90 b$ & $32.21 \pm 0.03 b$ \\
\hline Glucose & $42.86 \pm 0.31 \mathrm{~d}$ & $36.89 \pm 0.37 \mathrm{c}$ & $26.29 \pm 0.06 a$ & $26.67 \pm 0.03 \mathrm{a}$ & $31.64 \pm 0.12 b$ \\
\hline Sucrose & $1.65 \pm 0.27 \mathrm{a}$ & 0 & 0 & 0 & $3.03 \pm 0.02 b$ \\
\hline Sorbitol & $77.30 \pm 0.02 \mathrm{e}$ & $62.14 \pm 1.74 d$ & $35.77 \pm 0.37 a$ & $39.33 \pm 0.40 b$ & $43.70 \pm 0.21 \mathrm{c}$ \\
\hline Total & $162.37 \pm 0.35 \mathrm{e}$ & $140.21 \pm 2.30 \mathrm{~d}$ & $89.49 \pm 0.96 a$ & $99.26 \pm 2.32 b$ & $110.58 \pm 0.13 c$ \\
\hline \multicolumn{6}{|l|}{ Organic acids $(g / l)(n=3)$} \\
\hline Citric acid & $2.55 \pm 0.09 \mathrm{c}$ & $2.30 \pm 0.19 \mathrm{c}$ & $1.22 \pm 0.22 b$ & $0.98 \pm 0.13 b$ & $0.72 \pm 0.01 \mathrm{a}$ \\
\hline Malic acid & $13.33 \pm 0.79 \mathrm{~d}$ & $11.37 \pm 0.03 \mathrm{c}$ & $9.32 \pm 0.70 b$ & $9.40 \pm 0.91 b$ & $6.45 \pm 0.25 a$ \\
\hline Oxalic acid & $0.79 \pm 0.02 \mathrm{e}$ & $0.62 \pm 0.03 \mathrm{~d}$ & $0.17 \pm 0.02 \mathrm{a}$ & $0.35 \pm 0.03 c$ & $0.23 \pm 0.01 b$ \\
\hline Tartaric acid & $5.20 \pm 0.13 c$ & $4.66 \pm 0.16 \mathrm{a}$ & $5.10 \pm 0.15 b c$ & $5.18 \pm 0.04 c$ & $4.87 \pm 0.19 \mathrm{ab}$ \\
\hline Total & $21.87 \pm 0.88 \mathrm{~d}$ & $18.95 \pm 0.29 c$ & $15.81 \pm 0.97 b$ & $15.91 \pm 1.07 b$ & $12.27 \pm 0.33 a$ \\
\hline
\end{tabular}

Values are mean $\pm \mathrm{SD}$. Values that are followed by different letters within each row are significantly different $(p<0.05) ; n$ number of measurements

black chokeberry juices commercially available in Poland (Table 2). The total phenolic content estimated by HPLC method ranged from 1.00 to $1.45 \mathrm{~g} / \mathrm{l}$ and was six- or sevenfold lower than total phenolic content determined by Folin-Ciocalteu method (Tables 2, 3). It may confirm the significant contribution of polymeric proanthocyanidins in the phenolic compounds present in chokeberry juices. On the other hand, the Folin-Ciocalteu reagent is nonspecific to phenolic compounds and can react with a wide range of thiol derivatives, some vitamins and aromatic amino acids [30]. According to the literature data, proanthocyanidins are the dominant phenolic components of black chokeberry fruit and chokeberry juices [2, 3]. Additionally, $\mathrm{Wu}$ et al. [4] found that chokeberry fruits contained only procyanidins and polymers with DP $>10$ accounted for nearly $82 \%$ of total procyanidins content. Furthermore, the levels of total phenolics (2.73-10.35 g/l) and total anthocyanins $(0.10-0.67 \mathrm{~g} / \mathrm{l})$ estimated in this study agree with the literature data. Total phenolic content determined by the Folin-Ciocalteu method varied from 5.46 [31] to $18.54 \mathrm{~g} / \mathrm{l}$ [32], while total anthocyanin content estimated by $\mathrm{pH}$-differential method ranged from 0.15 [11] to $3.04 \mathrm{~g} / 1$ [6]. The large differentiation noticed in both the present and previous studies may be due to differences in chokeberry cultivars, maturation stages as well as technology of juice production, and time of the juice storage. Among chokeberry phenolic constituents, in particular, anthocyanins were extensively degraded (losses $93 \%$ ) during juice processing, while levels of hydroxycinnamic acids decreased by $37 \%$, proanthocyanins by $45 \%$, and flavonols by $48 \%$ [33]. On the other hand, Mayer-Miebach et al. [34] demonstrated high stability of phenolic compounds during chokeberries processing without enzyme treatment of mash.

The results of the present study revealed that all the chokeberry juices tested decreased pancreatic lipase activity in 4-MUO assay, while the inhibitory effect in lipid emulsions showed practically only two of them (Table 1). From a nutritional point of view, the use of different lipid emulsions as substrates for pancreatic lipase better resembles physiological conditions because dietary long-chain triglycerides are broken down into oil-in-water emulsions in mouth, stomach, and small intestine during digestion process [35]. The chokeberry juice brand 1 exhibited the lowest $\mathrm{IC}_{50}$ values and, therefore, the greatest inhibitory effect on pancreatic lipase (Table 1). This juice had the highest concentration of total phenolics and total proanthocyanidins (Table 2) as well as phenolic acids and anthocyanins determined by HPLC method (Table 3 ). The anti-lipase activity measured by fluorimetric method was correlated with the total phenolics $(r=-0.855)$, total anthocyanins $(r=-0.788)$, total proanthocyanidins $(r=-0.857)$, and the mDP of proanthocyanidins $(r=-0.830)$. For comparison, a Pearson's correlation coefficient between the $\mathrm{IC}_{50}$ value in triolein emulsion and total phenolics was 0.149 , total anthocyanins 0.460 , and total proanthocyanidins 0.063. Gironés-Vilaplana et al. [28] observed strong correlation between the lipase inhibition and anthocyanin content for Latin-American fruits. On the other hand, Boath et al. [25] suggested that anthocyanins are not necessary for lipase inhibition by berry polyphenols.

The lipase inhibition determined in triolein emulsion was correlated only with the $\mathrm{mDP}$ of proanthocyanidins 
$(r=-0.999)$. The mean size of proanthocyanidin molecules described by their $\mathrm{mDP}$ in the chokeberry juices tested was very diverse and ranged from 12 to 52, while for two more efficient juices was $>40$ (Table 2). For comparison, the $\mathrm{mDP}$ value for chokeberry juice obtained from heated fruits followed by decantation of raw juice was 24 [34]. The very high $\mathrm{mDP}$ values obtained in this study for juice brands 1 and 2 may indicate lack of enzyme treatment of chokeberry mash during fruit processing as well as decantation or filtration process of raw juice. The $\mathrm{mDP}$ of proanthocyanidins occurring in chokeberry fruit was determined as 59 [36] or in the acetone fruit extract as 19 [34]. The published studies have shown that anti-lipase activity of proanthocyanidins depends upon the degree of polymerization and more potent effect was observed for higher DP $[27,37]$. For example, the $\mathrm{IC}_{50}$ values determined with the use of 4-MUO as the substrate were as follows: for dimer $>125 \mu \mathrm{g} / \mathrm{ml}$, but 32.9 and only $0.9 \mu \mathrm{g} / \mathrm{ml}$ for trimer and procyanidins over nonamer, respectively [27]. Proanthocyanidins have been also postulated as the major factor responsible for the anti-lipase effect of apple, cocoa, and Salacia reticulata [27, 38, 39]. The role of proanthocyanidins in reducing obesity was recently reviewed by Salvadó et al. [40]. In vivo studies with different animal models confirm anti-obesity action of proanthocyanidins from various plant sources. Additionally, they also reduce the mass of adipose tissues and decrease body weight gain.

Nevertheless, chokeberry juice contains several classes of phenolic compounds which in combination might differently affect the lipase activity due to the different interaction between them as well as with other juice components. The results of qualitative and quantitative analyses of low molecular phenolic compounds by UPLC-MS and HPLC methods allowed to conclude that all most active juices had the same phenolic profile (Table 3), which was in accordance with the data published [9, 34]. The major low molecular phenolic compounds of chokeberry juice were chlorogenic acids such as 3- and 5- $O$-caffeoylquinic acid. The results published by Worsztynowicz et al. [13] used $p$-nitrophenol palmitate as substrate demonstrated that chlorogenic acids and anthocyanins, except for cyanidin 3 -glucoside, isolated from chokeberry fruit did not inhibit the pancreatic lipase. Unfortunately, authors of the above paper have not determined proanthocyanidins content in the extracts tested. In the assay using 4-MUO as substrate, the $\mathrm{IC}_{50}$ value for chlorogenic acid (the second low molecular phenolic in juices tested) was higher than that one for dimer but lower than the $\mathrm{IC}_{50}$ values for higher oligomers [27]. The differences in anti-lipase activity of chokeberry juices tested may be also due to nonphenolic components that may affect a surface property of the substrate emulsion and absorption of lipase at an oil-water interface. The juices tested in our studies differed also in terms of the basic chemical composition (Table 4). Total soluble solid, organic acid, sugars, and sorbitol contents were consistent with other report [1]. The low levels of sucrose in the juices studied are evidence that they were made purely from fruits without addition of sucrose. Additionally, the juice brand 1 with the highest anti-lipase activity had the highest soluble solids, glucose, sorbitol, and organic acids content.

Our results have also shown that commercially available black chokeberry juices may improve antioxidant status. It is a desired effect in the case of obesity which is considered as a state of chronic oxidative stress and inflammation related to reduced antioxidant defense and high reactive oxygen species production [41]. Antioxidant capacity was affected by the type of assay system and phenolic compounds contents. Additionally, the antioxidant capacity ranking order of the juices tested was slightly different than that one regarding the anti-lipase activity of the juices. The juice brand 3 with no anti-lipase activity in oils emulsions was the second in the order in terms of scavenging free radicals and ferric reducing power (Fig. 1). The antioxidant capacity as TE values was strongly correlated with total phenolics, anthocyanins, and proanthocyanidins $(r>0.934)$. We also observed a high correlation between antioxidant capacity and inhibition of pancreatic lipase measured by 4-MUO assay with a Pearson's correlation coefficient of $r>-0.740$. On the other hand, we have noticed lack of correlation between lipase inhibitory activity in triolein emulsion and antioxidant capacity. According to Zheng and Wang [42], among polyphenols present in chokeberry juice anthocyanins contribute the most to the total antioxidant activity ( $42 \%)$. Besides the anthocyanins, proanthocyanidins present in very high amounts in chokeberry juice are also very potent scavengers of free radicals as well as the inhibitors of lipid peroxidation [43, 44]. Moreover, black chokeberry juice phenolics were efficient in regenerating or protecting $\alpha$-tocopherol against oxidation [32].

\section{Conclusions}

In summary, the present study provides the first evidence that black chokeberry juices exhibited pancreatic lipase inhibition in vitro, which depends on the test method used. Additionally, our results suggested that the proanthocyanidins degree of polymerization was a very important factor responsible for the high inhibitory activity against pancreatic lipase. Therefore, proanthocyanidins-rich chokeberry juices as potent inhibitors of pancreatic lipase should be a component of a diet addressed to obese people as a natural alternative for obesity prophylaxis and treatment. This was the first study on inhibitory activity of chokeberry juice against pancreatic lipase. Moreover, consumption of black 
chokeberry juice may be a convenient and efficient way to supplement our diet with natural antioxidants capable of scavenging free radicals. Further studies are needed to examine the exact mechanism of the pancreatic lipase inhibition as well as influence of the chokeberry juice components on other digestive enzymes involved in degradation of carbohydrates and proteins.

Funding The work was funded by the National Science Centre allocated on the basis of Decision No. DEC-2011/01/B/NZ9/02046.

\section{Compliance with ethical standard}

\section{Conflict of interest None.}

Compliance with Ethics Requirements This article does not contain any studies with human or animal subjects.

Open Access This article is distributed under the terms of the Creative Commons Attribution 4.0 International License (http://creativecommons.org/licenses/by/4.0/), which permits unrestricted use, distribution, and reproduction in any medium, provided you give appropriate credit to the original author(s) and the source, provide a link to the Creative Commons license, and indicate if changes were made.

\section{References}

1. Kulling SE, Rawel HM (2008) Chokeberry (Aronia melanocarpa) - a review on the characteristic components and potential health effects. Planta Med 74:1625-1634

2. Denev P, Kratchanova M, Ciz M, Lojek A, Vasicek O, Nedelcheva P, Blazheva D, Toshkova R, Gardeva E, Yossifova L, Hyrsl P, Vojtek L (2014) Biological activities of selected polyphenol-rich fruits related to immunity and gastrointestinal health. Food Chem 157:37-44

3. Denev P, Lojek A, Kratchanova M (2013) Antioxidant activity and polyphenol content of Bulgarian fruits. Bulg J Agric Sci 19:22-27

4. Wu X, Gu L, Prior RL, McKay S (2004) Characterization of anthocyanins and proanthocyanidins in some cultivars of Ribes, Aronia and Sambucus and their antioxidant capacity. J Agric Food Chem 52:7846-7856

5. Chrubasik C, Li G, Chrubasik S (2010) The clinical effectiveness of chokeberry: a systematic review. Phytother Res 24:1107-1114

6. Jakobek L, Šeruga M, Medvidović-Kosanović M, Novak I (2007) Anthocyanin content and antioxidant activity of various red fruit juices. Deut Lebensm-Rundsch 1003:58-64

7. Kim JH, Auger C, Kurita I, Anselm E, Rivoarilala LO, Lee HJ, Lee KW, Schini-Kerth VB (2013) Aronia melanocarpa juice, a rich source of polyphenols, induces endothelium-dependent relaxations in porcine coronary arteries via the redox-sensitive activation of endothelial nitric oxide synthase. Nitric Oxide 35:54-64

8. Poręba R, Skoczyńska A, Gać P, Poręba M, Jędrychowska I, Affelska-Jercha A, Turczyn B, Wojakowska A, Oszmiański J, Andrzejak R (2009) Drinking of chokeberry juice from the ecological farm Dzięciołowo and distensibility of brachial artery in men with mild hypercholesterolemia. Ann Agric Environ Med 16:305-308

9. Krajka-Kuźniak V, Szaefer H, Ignatowicz E, Adamska T, Oszmiański J, Baer-Dubowska W (2009) Effect of chokeberry
(Aronia melanocarpa) juice on the metabolic activation and detoxication of carcinogenic $N$-nitrosodiethylamine in rat liver. J Agric Food Chem 57:5071-5077

10. Sharif T, Stambouli M, Burrus B, Emhemmed F, Dandache I, Auger C, Etienne-Selloum N, Schini-Kerth V, Fuhrmann G (2013) The polyphenolic-rich Aronia melanocarpa juice kills teratocarcinomal cancer stem-like cells, but not their differentiated counterparts. J Funct Foods 5:1244-1252

11. Zielińska-Przyjemska M, Olejnik A, Dobrowolska-Zachwieja A, Grajek W (2007) Effects of Aronia melanocarpa polyphenols on oxidative metabolism and apoptosis of neutrophilis from obese and non-obese individuals. Acta Sci Pol Technol Aliment 6:75-87

12. Podsędek A, Majewska I, Redzynia M, Sosnowska D, Koziołkiewicz M (2014) In vitro inhibitory effect on digestive enzymes and antioxidant potential of commonly consumed fruits. J Agric Food Chem 62:4610-4617

13. Worsztynowicz P, Napierała M, Białas W, Grajek W, Olkowicz M (2014) Pancreatic $\alpha$-amylase and lipase inhibitory activity of polyphenolic compounds present in the extract of black chokeberry (Aronia melanocarpa L.). Process Biochem 49:1457-1463

14. Mukherjee M (2003) Human digestive and metabolic lipases-a brief review. J Mol Catal B Enzym 22:369-376

15. Wilde PJ, Chu BS (2011) Interfacial and colloidal aspects of lipid digestion. Adv Colloid Interface Sci 165:14-22

16. Sójka M, Król B (2009) Composition of industrial seedless black currant pomace. Eur Food Res Technol 228:597-605

17. Rösch D, Bergmann M, Knorr D, Kroh LW (2003) Structureantioxidant efficiency relationships of phenolic compounds and their contribution to the antioxidant activity of sea buckthorn juice. J Agric Food Chem 51:4233-4239

18. Kucharska AZ, Szumny A, Sokół-Łętowska A, Piórecki N, Klymenko SV (2015) Iridoids and anthocyanins in cornelian cherry (Cornus mass L) cultivars. J Food Comp Anal 40:95-102

19. Wojdyło A, Oszmiański J, Bielicki P (2013) Polyphenolic composition, antioxidant activity, and polyphenol oxidase (PPO) activity of quince (Cydonia oblonga Miller) varieties. J Agric Food Chem 61:2762-2772

20. Sójka M, Klimczak E, Macierzyński J, Kołodziejczyk K (2013) Nutrient and polyphenolic composition of industrial strawberry press cake. Eur Food Res Technol 237:995-1007

21. Sosnowska D, Podsędek A, Redzynia M, Żyżelewicz D (2015) Effects of fruit extracts on pancreatic lipase activity in lipid emulsions. Plant Foods Hum Nutr 70:34-350

22. Re R, Pellegrini N, Proteggente A, Pannala A, Yang M, RiceEvans C (1999) Antioxidant activity applying an improved ABTS radical cation decolorization assay. Free Radical Bio Med 26:1231-1237

23. Kim DO, Lee KW, Lee HJ, Lee ChY (2002) Vitamin C equivalent antioxidant capacity (VCEAC) of phenolic phytochemicals. J Agric Food Chem 50:3713-3717

24. Benzie IFF, Strain JJ (1996) The ferric reducing ability of plasma (FRAP) as a measure of "antioxidant power": the FRAP assay. Anal Biochem 239:70-76

25. Boath AS, Grussu D, Stewart D, McDougall GJ (2012) Berry polyphenols inhibit digestive enzymes: a source of potential health benefits? Food Dig 3:1-7

26. McDougall GJ, Kulkarni NN, Stewart D (2009) Berry polyphenols inhibit pancreatic lipase activity in vitro. Food Chem 115:193-199

27. Sugiyama H, Akazome $Y$, Shoji T, Yamaguchi A, Yasue M, Kanda T, Ohtake Y (2007) Oligomeric procyanidins in apple polyphenol are main active components for inhibition of pancreatic lipase and triglyceride absorption. J Agric Food Chem 55:4604-4609

28. Gironés-Vilaplana A, Baenas N, Villaño D, Speisky H, GarciaViguera C, Moreno DA (2014) Evaluation of Latin-American 
fruits rich in phytochemicals with biological effects. J Funct Foods 7:599-608

29. Gironés-Vilaplana A, Moreno DA, Garcia-Viguera C (2014) Phytochemistry and biological activity of Spanish citrus fruits. Food Funct 5:764-772

30. Everette JD, Bryant QM, Green AM, Abbey YA, Wangila GW, Walker RB (2010) Thorough study of reactivity of various compound classes toward the Folin-Ciocalteu reagent. J Agric Food Chem 58:8139-8144

31. Eftimov M, Dobreva C, Velkova D, Valcheva-Kuzmanova S (2014) Effect of Aronia melanocarpa fruit juice on behaviour of rats exposed to social isolation. Trakia J Sci 12:123-126

32. Graversen HB, Becker EM, Skibsted LH, Andersen ML (2008) Antioxidant synergism between fruit juice and $\alpha$-tocopherol. A comparison between high phenolic black chokeberry (Aronia melanocarpa) and high ascorbic blackcurrant (Ribes nigrum). Eur Food Res Technol 226:737-743

33. Wilkes K, Howard LR, Brownmiller C, Prior RL (2014) Changes in chokeberry (Aronia melanocarpa L.) polyphenols during juice processing and storage. J Agric Food Chem 62:4018-4025

34. Mayer-Miebach E, Adamiuk M, Behsnilian D (2012) Stability of chokeberry bioactive polyphenols during juice processing and stabilization of a polyphenol-rich material from the by-product. Agriculture 2:244-258

35. McClements DJ, Li Y (2010) Review of in vitro digestion models for rapid screening of emulsion-based systems. Food Funct $1: 32-59$

36. Skupień K, Oszmiański J (2007) The effect of mineral fertilization on nutritive value and biological activity of chokeberry fruit. Agric Food Sci 16:46-55
37. Kimura H, Ogawa S, Akihiro T, Yokota K (2011) Structural analysis of A-type or B-type highly polymeric proanthocyanidins by thiolytic degradation and the implication in their inhibitory effects on pancreatic. J Chromatogr A 1218:7704-7712

38. Gu Y, Hurst WJ, Stuart DA, Lambert JD (2011) Inhibition of key digestive enzymes by cocoa extracts and procyanidins. J Agric Food Chem 59:5305-5311

39. Koga K, Hisamura M, Kanetaka T, Yoshino K, Matsuo Y, Tanaka T (2013) Proanthocyanidin oligomers isolated from Salacia reticulata leaves potently inhibit pancreatic lipase activity. J Food Sci 78:H105-H111

40. Salvadó MJ, Casanova E, Fernández-Iglesias A, Arola L, Bladé C (2015) Roles of proanthocyanidins rich extracts in obesity. Food Funct 6:1053-1071

41. Higdon JV, Frei B (2003) Obesity and oxidative stress: a direct link to CVD? Arterioscler Thromb Vasc 23:365-367

42. Zheng W, Wang SY (2003) Oxygen radical absorbing capacity of phenolics in blueberries, cranberries, chokeberries, and lingonberries. J Agric Food Chem 51:502-509

43. Lotito SB, Actis-Goretta L, Renart ML, Caligiuri M, Rein D, Schmitz HH, Steinberg F, Keen CL, Fraga CG (2000) Influence of oligomer chain length on the antioxidant activity of procyanidins. Biochem Biophys Res Commun 276:945-951

44. Faria A, Calhau C, de Freitas V, Mateus N (2006) Procyanidins as antioxidants and tumor cell growth modulators. J Agric Food Chem 54:2392-2397 